\title{
Penanaman Pohon pada Daerah Aliran Sungai di Desa Torongrejo Kota Batu dalam Mendukung Program Brantas Tuntas
}

\author{
Hisyam Fahmi ${ }^{1}$, Ahmad Abtokhi ${ }^{2}$ \\ 1,3 Jurusan Matematika, UIN Maulana Malik Ibrahim Malang \\ ${ }^{2}$ Jurusan Pendidikan Guru Madrasah Ibtidaiyah, UIN Maulana Malik Ibrahim Malang \\ hisyam.fahmi@uin-malang.ac.id
}

\section{Info Artikel}

Riwayat Artikel:

Diterima: Juni 2020

Direvisi: Juli 2020

Diterbitkan: September 2020

\section{Keywords:}

Clean the river

Brantas

Tree planting

\begin{abstract}
Changes in land use into settlements and agricultural land cause the falling rainwater to not directly penetrate the soil. The area in Torongrejo Village, Junrejo District is a sloping area so that the potential for flooding and erosion in this area is high. Soil and water conservation measures through tree planting movements involving the community is a strategic effort to reduce the danger of erosion and drain rainwater into the soil through the infiltration process. This activity was carried out in January 2020 and centered in Torongrejo Village. The service method used is in the form of community assistance, analysis and evaluation of tree planting and river cleaning. This tree planting activity was greeted enthusiastically by community components. There are about 150 tree seedlings planted around the Brantas river.
\end{abstract}

Copyright (C) 2020 JRCE. All rights reserved.

\section{Korespondensi:}

Hisyam Fahmi,

UIN Maulana Malik Ibrahim Malang,

Jl. Gajayana No. 50 Malang, Jawa Timur, Indonesia 65144

hisyam.fahmi@uin-malang.ac.id

\section{PENDAHULUAN}

Perguruan Tinggi harus mempersiapkan mahasiswa untuk berkontribusi di tengah-tengah masyarakat secara profesional [1], salah satunya dengan melakukan program Kuliah Kerja Nyata (KKN) yaitu pengabdian mahasiswa di masyarakat. KKN Tematik Brantas Tuntas [2] merupakan kolaborasi antara Pemerintahan Provinsi Jawa Timur dengan Perguruan Tinggi se-Jawa Timur yang didukung oleh Pemerintahan daerah dan masyarakat desa dalam menanggulangi permasalahan yang kerap muncul di sekitar aliran sungai Brantas di Jawa Timur. Salah satu wilayah yang dilalui sungai Brantas di daerah hulu adalah Kota Batu yang sangat berperan penting sebagai penangkal bencana seperti banjir dan tanah longsor di wilayah daerah aliran sungai (DAS) Brantas [3]. Luas wilayah hutan di daerah aliran sungai Brantas sudah semakin bertambah dari tahun-ketahun sejak 5 tahun terakhir [4].

Desa Torongrejo, Kecamatan Junrejo termasuk dalam daerah berpotensi tanah longsor dengan resiko rendah hingga sedang berdasarkan analisis dari Rema et al. [5]. Daerah zonasi resiko longsor di Desa Torongrejo seluas $287.14 \mathrm{~km} 2$ dengan resiko sedang dan $30.20 \mathrm{~km} 2$ dengan resiko rendah. Wilayah Desa Torongrejo menjadi wilayah yang berpotensi longsong paling tinggi jika dibandingkan dengan desa lain di Kecamatan Junrejo. Selain itu Desa Torongrejo merupakan daerah yang sudah sering terjadi banjir [6]. Hal ini tidak lain karena Desa Torongrejo merupakan salah satu desa yang dialiri sungai Brantas [7] dan semakin pesatnya pembangunan di pusat Kota Batu. 
Oleh karena itu, kegiatan KKN Mahasiswa ini bertujuan untuk memperbaiki kondisi hidro-orologi wilayah sekitar sungai Brantas termasuk mencegah banjir, erosi, dan melestarikan sumber daya air di Desa Torongrejo, Kecamatan Junrejo dengan melakukan penanaman bibit pohon di sekitar aliran sungai Brantas. Kegiatan ini juga menjadi aplikasi dari Program Brantas Tuntas melalui kolaborasi dengan pihak Perhutani Jawa Timur, Pemerintahan Desa, Karang Taruna Desa Torongrejo, dan beberapa komunitas lain seperti komunitas Arung Jeram.

\section{METODOLOGI}

\subsection{Sasaran Kegiatan}

Khalayak sasaran dari kegiatan ini adalah masyarakat Desa Torongrejo, Kecamatan Junrejo, Kota Batu yang terdiri atas 3 dusun, yaitu Dusun Klerek, Dusun Krajan, dan Dusun Ngukir. Namun hanya 2 dusun yang dilewati aliran sungai Brantas, yaitu Dusun Kelerek dan Dusun Ngukir, sehingga fokus kegiatan dilaksanakan di 2 dusun tersebut. Mahasiswa yang terlibat dalam kegiatan ini sebanyak 17 mahasiswa. Kegiatan ini juga bekerjasama dengan Pemerintah Desa setempat, Karang Taruna, Dinas Kehutanan Jawa Timur, dan komunitas Arung Jeram.

\subsection{Metode Kegiatan}

Kegiatan pengabdian masyarakat ini dilaksanakan dengan metode (1) pendampingan masyarakat dalam mendorong peningkatan partisipasi masyarakat; (2) analisis penyelesaian permasalahan dan penyusunan rencana; (3) evaluasi pelaksanaan kegiatan [8]. Sasaran utama program ini adalah kelompok masyarakat maupun individu yang peduli tinggi terhadap lingkungan dengan tujuan memberikan motivasi bagi masyarakat lainnya. Penentuan lokasi penanaman bibit melalui koordinasi dan diskusi dengan Pemerintah Desa dan Karang Taruna. Melakukan penghijauan pada lahan daerah sekitar sungai dan daerah rawan bencana dengan menanami bibitbibit pohon yang memiliki nilai ekonomis seperti sirsak, alpukat, dan mindi.

\section{HASIL DAN PEMBAHASAN}

\subsection{Penanaman Pohon di Sungai Brantas}

\subsubsection{Mekanisme Pelaksanaan Kegiatan}

Pelaksanaan kegiatan penghijauan disekitar sungai Brantas dilaksanakan dua kali, yaitu pada hari Jum'at, tanggal 17 januari 2020 dan hari Minggu, tanggal 19 januari 2020 pada pukul 09.00 sampai 11.30 WIB yang bertempat di Dusun Ngukir dan Dusun Klerek. Kegiatan ini dilaksanakan oleh peserta KKN mahasiswa bekerja sama dengan Karang Taruna, Pemerintah Desa dan Dinas Kehutanan Jawa Timur. Program ini merupakan Program Kerja Provinsi Jawa Timur yaitu Brantas Tuntas yang merupakan program pembenahan permasalahan yang ada di sungai khususnya Sungai Brantas. Salah satu isi program kerja dari program Brantas Tuntas adalah penghijauan yang ada disekitar Sungai Brantas. 


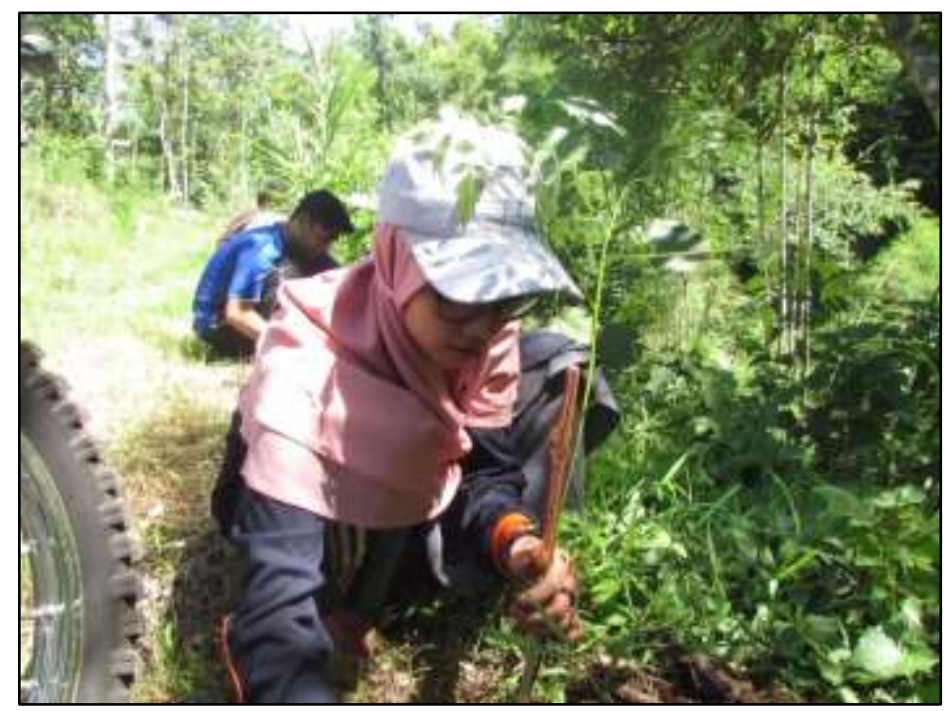

Gambar 1. Penanaman pohon di sekitar sungai Brantas

Bibit yang ditanam pada kegiatan penghijauan ini antara lain bibit pohon sirsak (Annona muricata), pohon alpukat (Persea americana), dan pohon mindi (Melia azedarach) dengan jumlah total keseluruhan bibit 150 pohon. Bibit yang didapatkan dalam kegiatan ini merupakan hasil koordinasi dengan Dinas Kehutanan Jawa Timur yang berada di desa Oro-oro Ombo. Pengambilan bibit dilakukan di Area Model Konservasi Edukasi (AMKE) dalam pengelolaan Gabungan Kelompok Tani (Gapoktan).

Kegiatan ini diikuti oleh anggota kelompok KKN mahasiswa dan anggota Karang Taruna Dusun Klerek, Desa Torongrejo. Koordinasi yang baik antar keduanya serta dukungan utama yang hadir dari bapak kepala Dusun Ngukir turut mendukung suksesnya kegiatan ini. Alat yang diperlukan dalam kegiatan penghijauan ini antara lain cangkul, sekop, bambu, dan lain-lain.

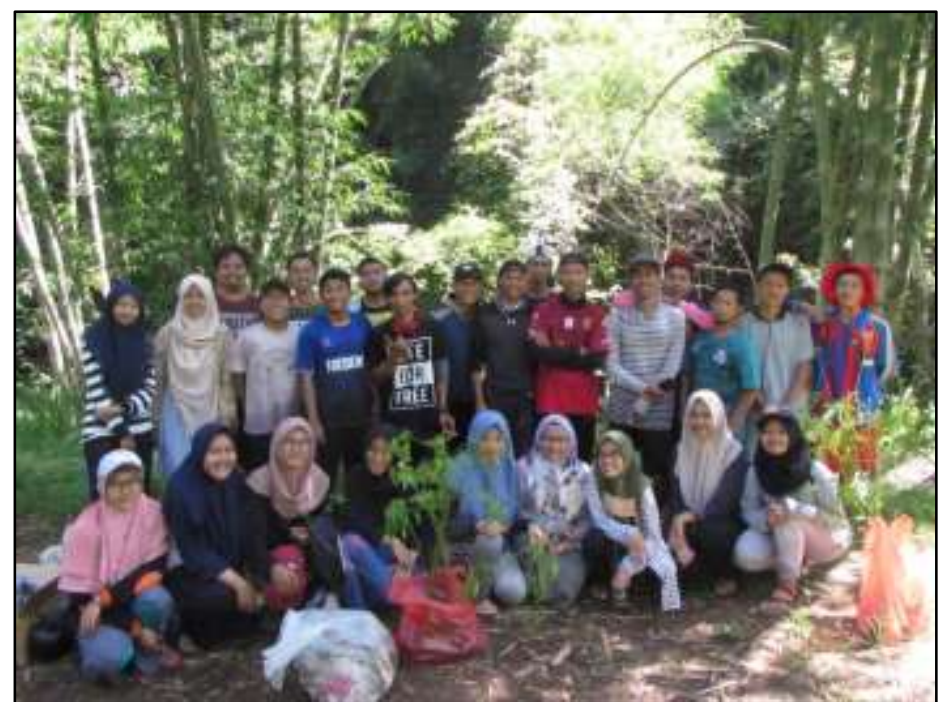

Gambar 2. Koordinasi anggota Kelompok KKN mahasiswa dengan pemuda Karang Taruna Dusun Klerek, Desa Torongrejo

\subsubsection{Permasalahan dalam Kegiatan Pelakasanaan}

Permasalahan yang dihadapi selama kegiatan ini berlangsung adalah pertama, kurangnya koordinasi yang mengakibatkan bibit pohon diambil lebih awal dari perkiraan pengambilan sehingga kurangnya persiapan dan akomodasi yang mengakibatkan bibit pohon tersebut dikemas dengan cara yang sangat sederhana. Kedua, cuaca yang tidak mendukung di tempat pengumpulan bibit sehingga bibit tersebut banyak yang menjadi layu bahkan mati. Ketiga, medan yang masih sangat alami sehingga untuk melakukan kegiatan tanam pohon yang kedua mengalami sedikit 
kendala dalam akomodasi menuju tempat pelaksanaan tanam pohon serta lahan yang digunakan masih dipenuhi oleh tumbuhan-tumbuhan liar. Sehingga masih perlunya pembersihan terhadap tanaman tanaman liar tersebut.

\subsubsection{Solusi Terhadap Masalah}

Solusi untuk menyelesaikan permasalahan diatas pertama yaitu hendaknya dilakukan koordinasi dengan Dinas Kehutanan Jawa Timur terkait pengambilan bibit, sehingga bibit pohon yang akan digunakan untuk kegiatan tersebut masih fresh dari tempat pengambilan bibit tanpa terhalang masalah cuaca yang mengakibatkan banyak bibit yang layu bahkan mati dan menyediakan tempat khusus untuk menyimpan bibit pohon yang diambil. Serta di kontrol setiap harinya agar pohon tersebut tetap terjaga kesehatannya. Lalu, menambah personil yang mengikuti kegiatan tanam pohon yang kedua agar kegiatan tersebut dapat dilakukan secara efektif dari segi waktu dengan membagi pekerjaan untuk menanam pohon dan membersihkan tanaman-tanaman liar.

\subsection{Pembersihan Sungai Brantas}

\subsubsection{Mekanisme Pelaksanaan Kegiatan}

Kegiatan pembersihan sungai Brantas dilakukan setelah pelaksanaan penanaman pohon di sungai Brantas. Kegiatan ini dilakukan pada hari Jum'at tanggal 17 Januari 2020. Pembersihan dilakukan oleh seluruh anggota kelompok KKN mahasiswa bersama dengan anggota Karang Taruna Desa Torongrejo, Kecamatan Junrejo, Kota Batu. Kegiatan pembersihan sungai Brantas dilakuan dengan tujuan untuk membersihkan sungai Brantas dari sampah plastik serta upaya menjaga kebersihan sungai Brantas yang digunakan sebagai jalur rafting.

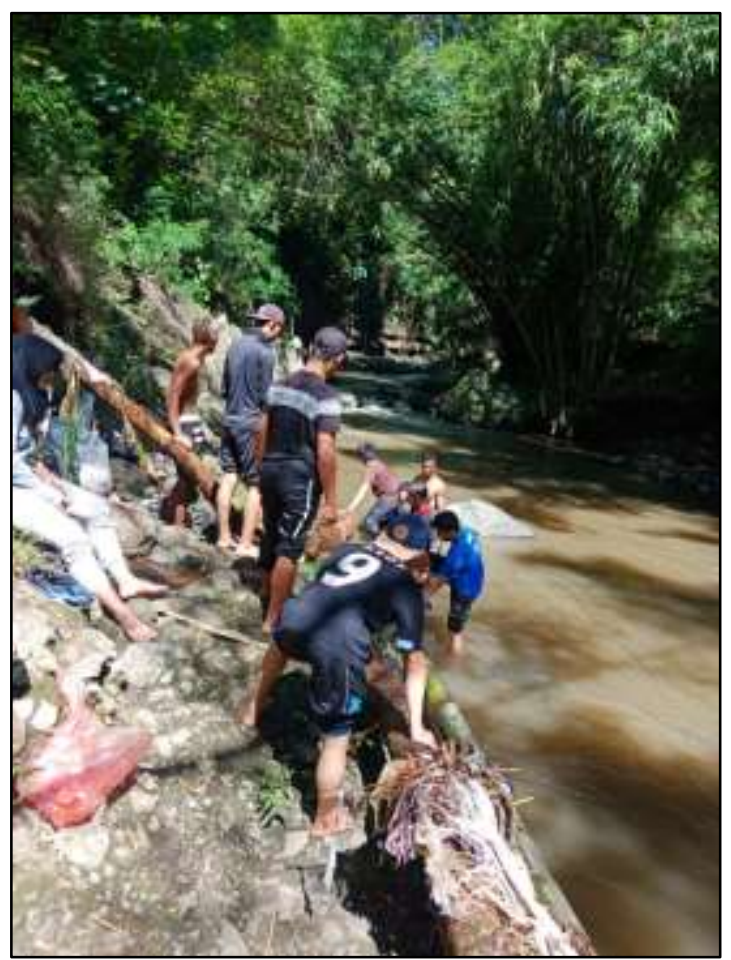

Gambar 3. Pembersihan sampah di sungai Brantas

Setelah penanaman pohon, seluruh anggota kelompok KKN dan Karang Taruna menuju sungai Brantas untuk melakukan kegiatan pembersihan seperti memungut sampah di daerah sungai dan membersihkan sungai dari pohon besar sekitar sungai yang tumbang. Sampah-sampah tersebut kemudian diambil dan dimasukkan ke kantong plastik untuk dibuang ke tempat sampah. Kegiatan pembersihan ini juga merupakan bagian dari Program Kerja Brantas Tuntas Provinsi Jawa Timur. Kegiatan ini merupakan program kerja yang berjangka panjang untuk sanitasi sungai agar bersih, indah, asri, dan tidak ada lagi penyebab wabah penyakit. 


\subsubsection{Permasalahan dalam Kegiatan}

Pada saat melakukan kegiatan pembersihan sungai Brantas terdapat beberapa masalah. Beberapa permasalahan tersebut diantaranya medan menuju sungai yang terjal dan bebatuan yang menyebabkan kesulitan untuk menuruni sungai. Selain itu, jalan yang licin juga membuat harus lebih berhati-hati saat melewati medan menuruni sungai Brantas. Kemudian, aliran sungai yang deras juga menghambat ketika pengambilan sampah. Selain sampah plastik juga terdapat pohon besar yang tumbang, yang bisa menjadi penghalang jalur rafting. Dibutuhkan waktu yang cukup lama untuk mengambil pohon tersebut yang kemudian dipindahkan di pinggir sungai Brantas.

\subsubsection{Solusi terhadap Masalah}

Berdasarkan permasalahan diatas terdapat alternatif solusi yang dilakukan, antara lain dilakukan gotong royong oleh anggota kelompok KKN mahasiswa dan Karang Taruna khususnya anggota laki-laki ketika memindahkan pohon besar ke pinggir sungai. Kemudian setelah memindahkan pohon, sampah-sampah yang terdapat di pohon diambil dan dibuang ke tempat sampah. Hal ini dilakukan dengan harapan jalur rafting dapat berjalan dengan baik dan menjaga kebersihan jalur wisata rafting. Alternatif lain yang seharusnya dilakukan yaitu mengadakan sosialisasi kepada masyarakat terhadap pentingnya menjaga kebersihan dan edukasi untuk tidak membuang sampah ke sungai yang dapat mencemari sungai.

\section{KESIMPULAN}

Kegiatan pengabdian kepada masyarakat melalui program KKN mahasiswa di Desa Torongrejo, Kecamatan Junrejo, Kota Batu bertujuan untuk mengatasi permasalahan yang muncul di masyarakat yaitu bencana banjir, erosi dan longsor yang diakibatkan oleh kondisi wilayah yang mengalami penurunan kualitas lingkungan karena kurang terjaganya ekosistem lingkungan di sekitar sungai Brantas. Kegiatan ini merupakan bentuk aplikasi Program Provinsi Jawa Timur, yaitu Brantas Tuntas untuk meningkatkan kualitas lingkungan dan masyarakat di Daerah Aliran Sungai Brantas, salah satunya adalah dengan kegiatan bersihbersih sungai dan penanaman pohon di sekitar aliran sungai Brantas. Kegiatan yang dilaksanakan oleh peserta KKN mahasiswa terlaksana dengan lancar karena dukungan dan koordinasi dari berbagai pihak, seperti Pemerintah Desa, Dinas Kehutanan Jawa Timur, dan Karang Taruna. Ada sekitar 150 bibit pohon yang ditanam, yang terdiri atas pohon alpukat, pohon sirsak, dan pohon mindi.

\section{UCAPAN TERIMAKASIH}

Terima kasih kepada Desa Torongrejo, Kecamatan Junrejo, Kota Batu yang telah bersedia ditempati untuk melaksanakan program Kuliah Kerja Mahasiswa (KKM) UIN Maulana Malik Ibrahim Malang tahun 2020. Terima kasih kepada Dinas Kehutanan Provinsi Jawa Timur yang telah menyediakan bibit pohon untuk kegiatan tanam pohon di DAS Brantas. Terima kasih juga kepada Lembaga Penelitian dan Pengabdian Masyarakat (LP2M) UIN Maulana Malik Ibrahim Malang yang telah memfasilitasi kegiatan KKM ke desadesa.

\section{DAFTAR PUSTAKA}

[1] M.-A. Szitar, "Learning about Sustainable Community Development," Procedia - Soc. Behav. Sci., vol. 116, pp. 3462-3466, Feb. 2014.

[2] LP2M Universitas Jember, "Pedoman Kuliah Kerja Nyata (KKN) Kolaboratif PTN se Jawa Timur Brantas Tuntas," 2020.

[3] M. M. Mahzum and M. A. Mardyanto, "Analisis Ketersediaan Sumber Daya Air dan Upaya Konservasi Sub DAS Brantas Hulu Wilayah Kota Batu,” Institut Teknologi Sepuluh Nopember, 2015.

[4] K. Yoshino, Y. Setiawan, and E. Shima, "Land Use Analysis using Time Series of Vegetation Index Derived from Satellite Remote Sensing in Brantas River Watershed," J. Geomatics Plan., vol. 4, no. 2, pp. 109-120, 2017.

[5] Y. Moses et al., "Zonasi kawasan berdasarkan tingkat risiko bencana tanah longsor di Kota Batu (Provinsi Jawa Timur)," Institut Teknologi Nasional Malang, 2019.

[6] "Torongrejo Langganan Banjir, Warga Salahkan Pembangunan di Kota Batu - Arema Media." [Online]. Available: http://aremamedia.com/torongrejo-langganan-banjir-warga-salahkan-pembangunan-di-kota-batu/. [Accessed: 26-Feb-2020]. 
[7] "Musim Hujan, Ini Titik Rawan Bencana di Kota Batu - MalangVoice.” [Online]. Available: https://malangvoice.com/musim-hujan-ini-titik-rawan-bencana-di-kota-batu/. [Accessed: 26-Feb-2020].

[8] S. S. Arifin, M. R. Syukri, and M. I. D. Kalamang, "Program IPTEKS bagi Wilayah (IbW) Kecamatan Kota Barat Kota Gorontalo," Gorontalo, 2015. 